\title{
Gallbladder carcinoma associated with anomalous pancreaticobiliary duct junction
}

\author{
Chang Moo Kang MD, Kyung Sik Kim MD, Jin Sub Choi MD, Woo Jung Lee MD, Byong Ro Kim MD
}

CM Kang, KS Kim, JS Choi, WJ Lee, BR Kim. Gallbladder carcinoma associated with anomalous pancreaticobiliary duct junction. Can J Gastroenterol 2007;21(6):383-387.

BACKGROUND: Anomalous pancreaticobiliary ductal junction (APBDJ) is believed to be one of the risk factors for gallbladder carcinoma. The present study aims to delineate the gallbladder carcinoma characteristics associated with APBDJ.

PATIENTS AND METHODS: Patients with gallbladder carcinoma associated with APBDJ between August 1992 and February 2005 were retrospectively reviewed. Two types of APBDJ classifications were considered: right-angle type (C-P) and acute-angle type (P-C).

RESULTS: Ten of 218 patients $(4.6 \%)$ with gallbladder carcinomas were associated with APBDJ. All patients were female with a mean age of 55.4 years (range 41 to 72 years). Gallstones were absent in nine patients. Seven patients (70\%) had the P-C type and three patients (30\%) had the C-P type. Survival differences between the P-C type and the C-P type of gallbladder carcinomas were noted $(\mathrm{P}=0.0269)$. Patients with incidentally detected gallbladder carcinoma had superior survival $(\mathrm{P}=0.0316)$.

CONCLUSION: Gallbladder carcinomas associated with APBDJ were significantly related to relatively young female patients without gallbladder stones. Survival outcomes in these patients were not different from those of gallbladder carcinoma without APBDJ. In particular, the P-C type of APBDJ seemed to be more associated with relatively advanced gallbladder carcinomas, and patients with incidentally detected gallbladder carcinomas with APBDJ had superior survival.
Cancer de la vésicule associé à des anomalies de la jonction du canal pancréaticobiliaire

Key Words: Anomalous pancreaticobiliary duct junction; Gallbladder carcinoma

Gallbladder carcinoma is ranked fifth in incidence among Jall gastrointestinal carcinomas. One of the well-known risk factors is anomalous pancreaticobiliary ductal junction (APBDJ) (1). This congenital condition can be defined as the junction between the choledochus and the pancreatic duct located outside of the duodenal wall and beyond the influence of the sphincter of Oddi (2-4). APBDJ is believed to be commonly associated with various biliary and pancreatic disorders, including choledochal cysts, recurrent pancreatitis, and precancerous and cancerous biliary tract conditions (5-7). Approximately $80 \%$ of APBDJ patients have congenital choledochal cysts. The occurrence rate of biliary tract carcinoma of the gallbladder is between $3 \%$ and $18 \%$, while the rate of biliary tract carcinoma of the extrahepatic bile duct is at least $33 \%$ to $54 \%$ (8).

APBDJ is well known as a risk factor for developing carcinoma of the gallbladder. Recently, Nuzzo et al (9) reported three

\begin{abstract}
HISTORIQUE : Une anomalie au niveau de la jonction du canal pancréaticobiliaire (AJCPB) serait un facteur de risque de cancer de la vésicule. La présente étude vise à déterminer les caractéristiques du cancer de la vésicule associé à l'AJCPB.

PATIENTS ET MÉTHODES : Les cas de cancer de la vésicule associé à une $\mathrm{AJCPB}$ entre août 1992 et février 2005 ont été passés en revue de manière rétrospective. Deux types de classification d'AJCPB ont été considérés : le type dit à angle droit (C-P) et le type dit à angle aigu (P-C). RÉSULTATS : Dix patients sur 218 (4,6\%) étaient atteints d'un cancer associé à une AJCPB. Tous les patients étaient de sexe féminin et âgés en moyenne de 55,4 ans (entre 41 et 72 ans). Neuf patientes ne présentaient pas de calculs biliaires. Sept $(70 \%)$ présentaient le type P-C et trois ( $30 \%$ ), le type C-P. Les différences de survie selon le type P-C ou le type C-P de cancer de la vésicule ont été notées $(p=0,0269)$. Les patientes chez qui le cancer de la vésicule avait été décelé de manière fortuite ont présenté une survie plus grande $(\mathrm{p}=0,0316)$.

CONCLUSION : Les cancers de la vésicule associés à une AJCPB ont été en lien significatif avec l'âge relativement jeune des patientes, qui par ailleurs, ne présentaient pas de calculs biliaires. Les données de survie n'ont pas été différentes chez ces patientes comparativement au cancer de la vésicule non lié à une $\mathrm{AJCPB}$. Le type $\mathrm{P}-\mathrm{C}$ d'AJCPB, en particulier, a semblé davantage associé à des cancers de la vésicule relativement plus avancés. Les patientes atteintes de cancers de la vésicule associés à une AJCPB détectés fortuitement ont présenté une meilleure survie.
\end{abstract}

cases of papillary carcinoma of the gallbladder and APBDJ, presenting frequent associations between papillary carcinoma of the gallbladder and APBDJ. However, the characteristics of gallbladder carcinoma associated with APBDJ were not thoroughly investigated. Therefore, the present study aimed to delineate the characteristics of gallbladder carcinoma associated with APBDJ.

\section{PATIENTS AND METHODS}

The available medical records of patients who had been diagnosed and surgically treated between August 1992 and February 2005 with gallbladder carcinoma associated with APBDJ were retrospectively reviewed.

APBDJ was defined as a union of the pancreatic and biliary duct located outside the duodenal wall. In the past, APBDJ has been defined according to the types of confluence between the terminal common bile duct and the pancreatic duct. However, our

Department of Surgery, Yonsei University College of Medicine, Seoul, Korea

Correspondence and reprints: Dr Woo Jung Lee, 120-752, Department of Surgery, Yonsei University College of Medicine, 134 Shinchon-dong,

Seodaemun-gu, Seoul, Korea. Telephone 82-2-2228-2122, fax 82-2-313-8289, e-mail wjlee@yumc.younsei.ac.kr or

cmkang@yumc.yonsei.ac.kr

Received for publication July 31, 2006. Accepted August 31, 2006 

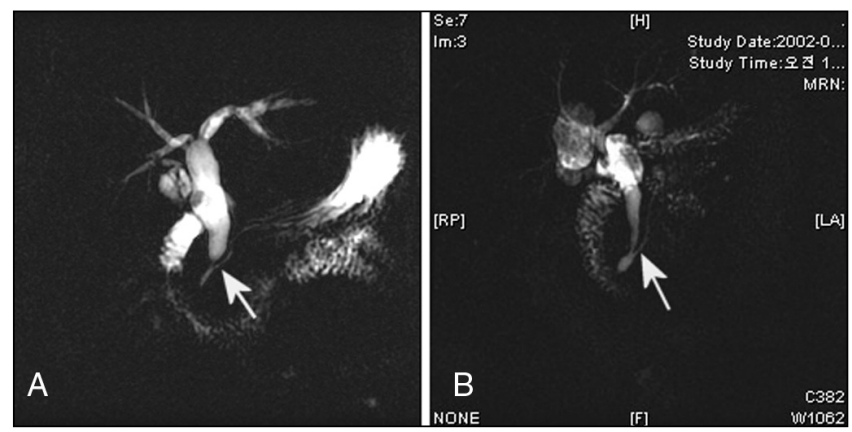

Figure 1) Classification of anomalous pancreaticobiliary ductal junction. A The right-angle type, when the common bile duct appears to join the main pancreatic duct (arrow). B The acute-angle type, when the main pancreatic duct appears to join the common bile duct (arrow)

study designed the following two types of APBDJ classification (Figure 1) - the choledochal or right-angle type (C-P type), when the common bile duct appears to join the pancreatic duct, and the pancreatic or acute-angle type (P-C type), when the pancreatic duct is likely to join the distal common bile duct. The sixth edition of the AJCC Cancer Staging Manual (10) was used for staging the gallbladder carcinoma.

Data on patients' general characteristics, the types of APBDJ and survival time were retrospectively collected based on the available medical records and radiological imaging studies. Statistical analyses were performed using SPSS version 10.00 (SPSS Inc, USA). The categorical variables were expressed as frequencies (percentages), and continuous variables were presented as means (ranges). Survival time was calculated from the date of diagnosis to the date of death or the date of the last follow-up. Overall, survival rates were estimated using the KaplanMeier method and were checked for statistical significance by the log-rank test. $\mathrm{P}<0.05$ was considered to be significant.

\section{RESULTS}

General characteristics of the patients

Among the 218 patients who were diagnosed with gallbladder carcinoma and surgically treated during the observation period, 10 cases of gallbladder carcinoma (4.6\%) were associated with APBDJ. All patients were female, with a mean age of 55.4 years (range 41 to 72 years). The presenting symptoms were generally nonspecific. The most frequent symptom, which was noted in seven patients, was abdominal pain in the right upper quadrant or the epigastric area (Table 1). The mean duration of the presenting symptoms was 9.9 months (range 0.5 to 24 months). Gallstones were absent in nine of 10 patients. In comparison, 78 of 198 patients (39.8\%) with gallbladder carcinoma without APBDJ had associated gallbladder stones $(P=0.078)$. Five cases of gallbladder carcinoma with APBDJ were found incidentally. Two of these cases were found during regular health check-ups, and the other three cases were detected during the surgical correction of choledochal cysts.

\section{APBDJ and choledochal cyst characteristics}

Seven patients (70\%) had choledochal cysts. Choledochal cyst type I (cystic $[n=1]$ and cylindrical $[n=5]$ ) was the most frequently observed and was found in six patients. In contrast, choledochal cyst type II (diverticular) was noted in only one study patient. The remaining three patients did not have
TABLE 1

Symptoms of gallbladder carcinoma associated with anomalous pancreaticobiliary ductal junction

\begin{tabular}{lc}
\hline Symptoms & $\begin{array}{c}\text { Frequency } \\
\text { (n) }\end{array}$ \\
\hline Abdominal pain & 7 \\
Indigestion & 2 \\
Weight loss & 2 \\
Fever or chills & 2 \\
General weakness & 2 \\
Anorexia & 2 \\
Jaundice & 1 \\
Pancreatitis & 1 \\
\hline
\end{tabular}

congenital cystic dilation of the bile duct. Seven patients (70\%) with gallbladder carcinoma associated with APBDJ had the P-C type of APBDJ and the remaining three patients (30\%) had the C-P type.

Characteristics of gallbladder carcinoma

All gallbladder carcinomas associated with APBDJ were adenocarcinomas. Apparently, gallbladder carcinomas associated with the $\mathrm{P}-\mathrm{C}$ type were relatively advanced cases $(\mathrm{P}=0.067)$. All patients with the P-C type of APBDJ had gallbladder carcinomas that extended over the muscular layer (T2). In particular, five of seven patients (71.4\%) with the P-C type of APBDJ had gallbladder carcinomas with T3 lesions. As a result, three patients $(42.9 \%)$ could not undergo resection for their gallbladder carcinomas. In contrast, two patients with the C-P type APBDJ had gallbladder carcinomas with lesions of a stage less than T1b, and only one patient had a T2 lesion. All three of these patients could undergo gallbladder carcinoma resections. Tumour grade and surgical treatment are also listed in Table 2.

Survival rates of patients with gallbladder carcinoma associated with APBDJ

The overall mean survival time of patients with gallbladder carcinoma associated with APBDJ was estimated to be about 61.3 months (95\% CI 21.03 to 101.5 months). This value was not significantly different from the survival rate of patients with gallbladder carcinoma not associated with APBDJ (mean survival time 62.9 months, $95 \%$ CI 52.44 to 73.34 months, $\mathrm{P}=0.8161$ ) (Figure 2).

Interestingly, survival time differences were found between the P-C type and the C-P type of gallbladder carcinomas. All patients with the C-P type of gallbladder carcinoma survived without any cancer-related mortality. However, the mean survival time of the P-C type of gallbladder carcinoma was 21.8 months (95\% CI 6.05 to 37.47 months, $\mathrm{P}=0.0269$ [Figure 3]). In addition, patients with incidentally detected gallbladder carcinoma had superior survival time over patients with gallbladder carcinoma that had been preoperatively diagnosed (mean survival time 93.9 months, 95\% CI 42.78 to 145.07 months versus mean survival time 14.2 months, $95 \%$ CI 2.48 to 25.93 months, $\mathrm{P}=0.0316$ [Figure 4]).

\section{DISCUSSION}

APBDJ can be diagnosed when the junction between the pancreatic and biliary ducts is located outside the duodenal wall 
TABLE 2

Summary of female patients $(n=10)$ with gallbladder carcinoma associated with anomalous pancreaticobiliary ductal junction (APBDJ)

\begin{tabular}{|c|c|c|c|c|c|c|c|}
\hline Age $^{*}$ & Sex & $\begin{array}{l}\text { Type of } \\
\text { APBDJ }\end{array}$ & CDC & $\begin{array}{l}\text { Tumour } \\
\text { stage }\end{array}$ & $\begin{array}{l}\text { Tumour } \\
\text { grade }\end{array}$ & Operation & $\mathbf{S R}^{\dagger}$ \\
\hline 72 & $\mathrm{~F}$ & C-P & Yes & TIbNOMO & Well & $\begin{array}{l}\text { Cholecystectomy, } \\
\text { cystoduodenostom }\end{array}$ & 143 \\
\hline 51 & $\mathrm{~F}$ & C-P & No & TisNOMO & - & Cholecystectomy & 138 \\
\hline 56 & $\mathrm{~F}$ & $\mathrm{P}-\mathrm{C}$ & No & T4N1M0 & Poor & Unresectable & 8 \\
\hline 53 & $\mathrm{~F}$ & $\mathrm{P}-\mathrm{C}$ & Yes & T2NOMO & Moderate & Correction of CDC & 51 \\
\hline 52 & $\mathrm{~F}$ & $\mathrm{P}-\mathrm{C}$ & Yes & T4N1M0 & - & Unresectable & 6 \\
\hline 41 & $\mathrm{~F}$ & $\mathrm{P}-\mathrm{C}$ & Yes & T3N1M1 & Poor & Cholecystectomy & 18 \\
\hline 54 & $\mathrm{~F}$ & $\mathrm{P}-\mathrm{C}$ & No & T2NOMO & Well & $R C+P P P D$ & 40 \\
\hline 56 & $\mathrm{~F}$ & $\mathrm{P}-\mathrm{C}$ & Yes & T3N1M0 & Poor & $\mathrm{RC}$ & 10 \\
\hline 63 & $\mathrm{~F}$ & $\mathrm{P}-\mathrm{C}$ & Yes & T4N1M1 & Poor & Unresectable & 5 \\
\hline 56 & $\mathrm{~F}$ & C-P & Yes & T2N1M0 & Poor & Correction of CDC & 20 \\
\hline
\end{tabular}

*Age in years; 'Survival rates (SR) in months. C-P Right-angle type of APB$D J ;$ CDC Choledochal cyst; P-C Acute-angle type of APBDJ; PPPD Pyloruspreserving pancreaticoduodenectomy; $R C$ Radical cholecystectomy

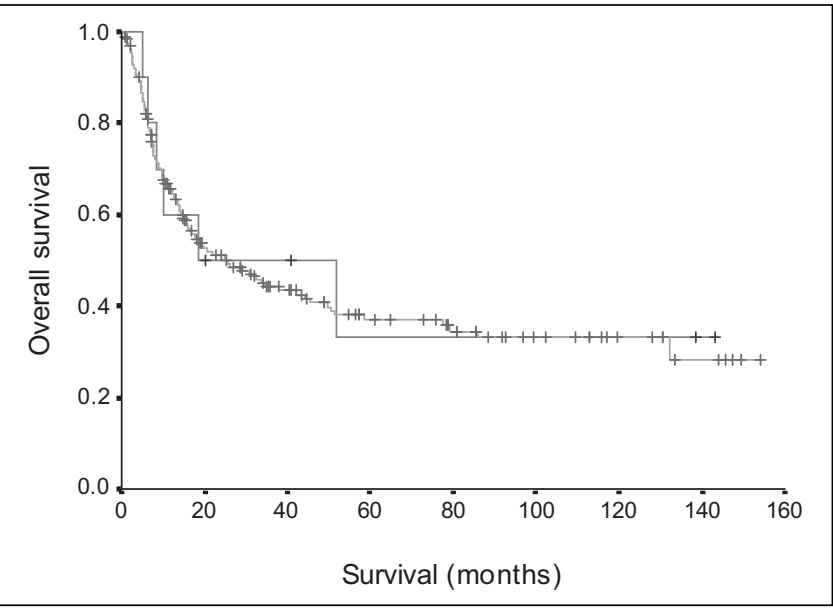

Figure 2) Overall survival rate of gallbladder carcinoma associated with anomalous pancreaticobiliary ductal junction $(P=0.8161)$

and forms a long common channel $15 \mathrm{~mm}$ long or longer (11), which is noted on biliary images such as endoscopic retrograde cholangiopancreatography (ERCP), percutaneous transhepatic cholangiography and magnetic resonance cholangiopancreatography. This condition has been increasingly detected since the introduction of ERCP and percutaneous transhepatic cholangiography (12). The reported frequency of APBDJ on ERCP ranges from $1.5 \%$ to $8.7 \%(5,6,13)$. According to a report of our institution (16), 45 cases of APBDJ were detected among 8951 ERCP cases (thus, the overall incidence of APBDJ was $0.50 \%$ [45 of 8951]); however, over the past five years, a period in which the concept of APBDJ has been generalized, the incidence of this malformation has been $0.85 \%$ (39 of 4607). The prevalence of APBDJ has been reported to be high in Asian countries $(6,13)$. This condition is believed to be commonly associated with both pancreatic and biliary tract pathologies such as choledochal cysts, choledocholithiasis and biliary tract carcinoma. To the best of our knowledge, several reports have been released suggesting close association of APBDJ, especially

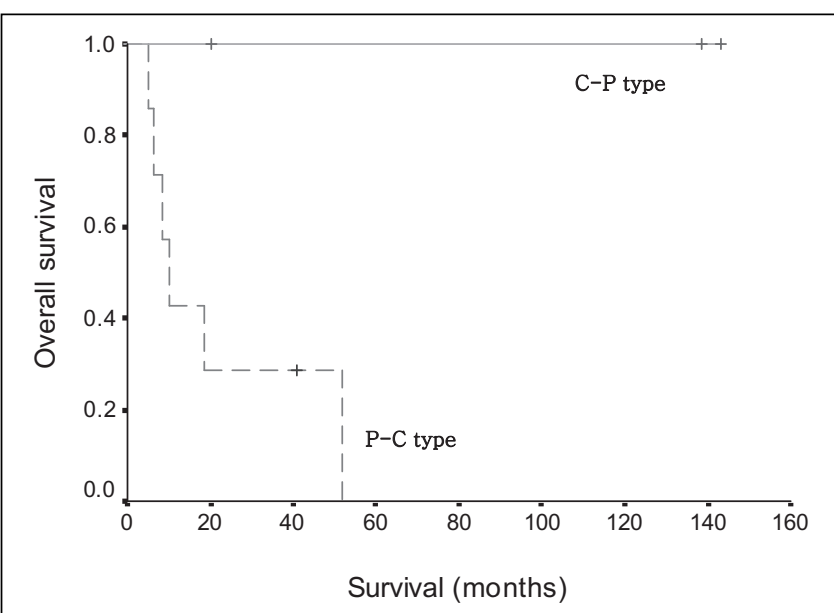

Figure 3) Survival time differences between gallbladder carcinoma patients with the acute-angle (P-C) type and the right-angle (C-P) type of anomalous pancreaticobiliary ductal junction $(P=0.0269)$

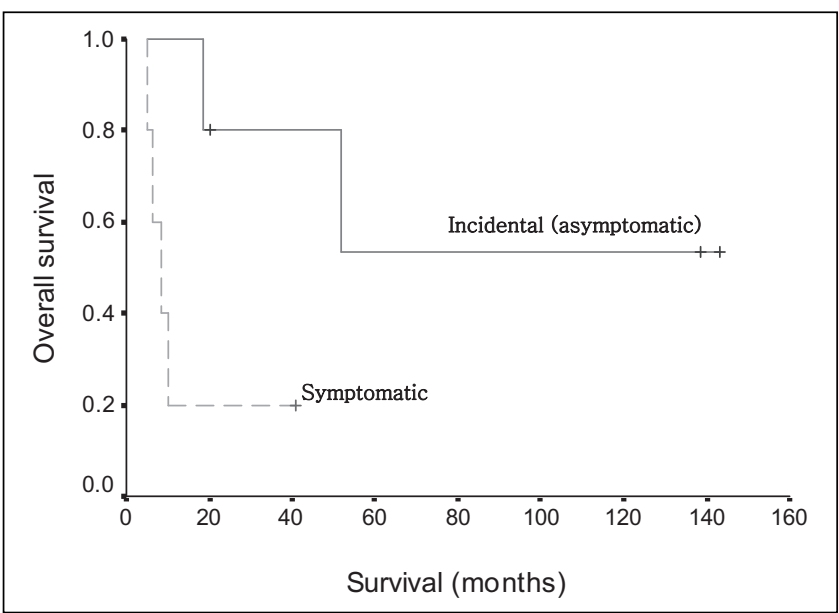

Figure 4) Survival time differences between incidentally detected and preoperatively diagnosed gallbladder carcinoma associated with anomalous pancreaticobiliary ductal junction $(P=0.0316)$

the P-C type, with gallbladder carcinoma $(12,13,15,16)$; however, there seems to be no reports that have a particular focus on the characteristics of gallbladder carcinoma associated with APBDJ. Therefore, our study aimed to define the characteristics of gallbladder carcinoma associated with APBDJ.

According to our data, several characteristics of gallbladder carcinoma associated with APBDJ can be delineated. First, although statistical analysis could not reveal the significant differences in age between the two groups, our data showed that gallbladder carcinomas associated with APBDJ were found in younger patients than those with gallbladder carcinomas not associated with APBDJ $(55.4 \pm 8.03$ years versus $61.9 \pm 10.76$ years, $\mathrm{P}=0.063)$. This observation is similar to other reports (10). Second, all patients with gallbladder carcinoma associated with APBDJ were female; therefore, female patients could have gallbladder carcinoma associated with APBDJ more frequently than gallbladder carcinoma not associated with APBDJ (108 of 207 female patients versus 10 of 10 female patients, $\mathrm{P}=0.002$, using $\chi^{2}$ and Fisher's exact tests). This finding may not be surprising because choledochal cysts, which are well known to be most common in female patients have also 
been associated with APBDJ (17). Third, patients with gallbladder carcinoma with APBDJ had a tendency not to have simultaneous gallstones. This result is also similar to another report in the literature (17). Hu et al (12) reported that no gallstone diseases were linked to gallbladder carcinoma associated with APBDJ. Lastly, overall survival time of the patients with gallbladder carcinoma associated with APBDJ was not significantly different from those without APBDJ $(\mathrm{P}=0.8161)$. However, considerable survival time differences were noted between patients with gallbladder carcinomas associated with the P-C type of APBDJ and those with the C-P type of APBDJ $(\mathrm{P}=0.0269)$. This is an easily expected result, because more advanced gallbladder carcinomas were more frequently found in patients with the P-C type of APBDJ.

A relationship between APBDJ and gallbladder carcinoma was established in the 1980s. It is generally accepted that the reflux of pancreatic juice into the biliary tract in patients with APBDJ is the causative factor for biliary tract cancers. Because the hydrostatic pressure within the pancreatic duct is higher than the pressure within the bile duct, pancreatic juice flows easily into the bile duct of APBDJ patients. This can lead to chronic inflammation in the biliary tract and changes in the bile constituents. These constituent changes possibly result from reactions between pancreatic enzymes and bile contents, such as the reaction between phospholipase A2 and lecithin (18). Chronic inflammation and cytotoxic metabolites presumably stimulate gallbladder transformation into premalignant lesions, which include intestinal metaplasia, hyperplasia or dysplasia. All these lesion types are associated with the mutations of $p 53$ and K-ras $(19,20)$. Based on our results, it is postulated that the $\mathrm{P}-\mathrm{C}$ type of $\mathrm{APBDJ}$ may provide more chances for the pancreatic juice to reflux into the bile duct than the C-P type of APBDJ because of its physiological properties. For example, the angle differences of the confluences between the pancreatic duct and the bile duct may possibly be attributed to pancreatic juice which refluxes into the biliary system more easily in the P-C type of APBDJ. This mechanism may be initiated very early in a patient's life, because APDBJ is a congenital condition. Therefore, gallbladder carcinoma associated with APBDJ may develop earlier than those without APBDJ, and the injury caused by the reflux mechanism of pancreatic juice into the bile duct is more severe in the $\mathrm{P}-\mathrm{C}$ type of APBDJ than in the C-P type of APBDJ. This may result in more advanced gallbladder carcinoma during the period of carcinogenesis.

According to the literature (21), the incidence of gallbladder carcinoma associated with APBDJ is approximately $10 \%$. The incidence in our study was approximately $4.6 \%$, which is apparently lower than in previous studies. This difference can be explained by the fact that our study was based on retrospective data. All the patients in our study did not have ERCP or magnetic resonance cholangiopancreatography, which could have shown the exact relationship between the choledochus and the pancreatic duct. As a result, there is a high probability that our database of gallbladder carcinoma without APBDJ encompasses several cases of undetected gallbladder carcinoma associated with APBDJ.

At present, it is difficult to address the exact percentage of patients with APBDJ who have developed gallbladder carcinoma, because currently, we do not have cohort data on APBDJ. However, cross-sectional observation can roughly estimate the incidence of gallbladder carcinoma among patients with APBDJ. One hundred seven patients were diagnosed with APBDJ during the same period of current study. Among them, 10 patients had concomitant gallbladder carcinoma, indicating that the incidence of gallbladder carcinoma among APBDJ patients is approximately 9.3\% (10 gallbladder carcinomas out of 107 APBDJs). However, this incidence may underestimate the real incidence of gallbladder carcinomas among patients with APBDJ.

\section{CONCLUSION}

Our retrospective observation showed that gallbladder carcinomas associated with APBDJ were found significantly more often in young female patients without gallbladder stones. Survival outcomes in these patients were not different from patients with gallbladder carcinoma without APBDJ. In particular, the P-C type of APBDJ seems to be more associated with advanced gallbladder carcinoma, and patients with incidentally detected gallbladder carcinomas with APBDJ had superior survival time than those with diagnosis of gallbladder carcinoma before surgery.

ACKNOWLEDGEMENTS: The authors especially thank Professor Myeong Jin Kim (Yonsei University College of Medicine, Department of Radiology) for linguistic comments on the radiological images presented in this manuscript. Comments from Kyung Hee Ko (Ponchon Cha University College of Medicine, Department of Radiology), Seung Min Bang (Yonsei University College of Medicine, Department of Internal Medicine) and Mi Suk Park (Yonsei University College of Medicine, Department of Radiology) were also appreciated.

\section{REFERENCES}

1. Kato O, Hattori K, Suzuki T, Tachino F, Yuasa T. Clinical significance of anomalous pancreaticobiliary union. Gastrointest Endosc 1983;29:94-8.

2. Guelrud M, Morera C, Rodriguez M, Jaen D, Pierre R. Sphincter of Oddi dysfunction in children with recurrent pancreatitis and anomalous pancreaticobiliary union: An etiologic concept. Gastrointest Endosc 1999;50:194-9.

3. Guelrud M, Morera C, Rodriguez M, Prados JG, Jaen D. Normal and anomalous pancreaticobiliary union in children and adolescents. Gastrointest Endosc 1999;50:189-93.

4. Ohtsuka T, Inoue K, Ohuchida J, et al. Carcinoma arising in choledochocele. Endoscopy 2001;33:614-9.

5. Yamauchi S, Koga A, Matsumoto S, Tanaka M, Nakayama F. Anomalous junction of pancreaticobiliary duct without congenital choledochal cyst: A possible risk factor for gallbladder cancer. Am J Gastroenterol 1987:82;20-4.

6. Kimura K, Ohto M, Saisho H, et al. Association of gallbladder carcinoma and anomalous pancreaticobiliary ductal union. Gastroenterology 1985;89:1258-65.

7. Sandoh N, Shirai Y, Hatakeyama K. Incidence of anomalous union of the pancreaticobiliary ductal system in biliary cancer. Hepatogastroenterology 1997;44:1580-3.

8. Chijiiwa K, Tanaka M. [Carcinoma of the gallbladder in anomalous pancreaticobiliary ductal junction]. Nippon Geka Gakkai Zasshi 1996;97:599-605.

9. Nuzzo G, Clemente G, Cadeddu F, Ardito F, Ricci R, Vecchio FM. Papillary carcinoma of the gallbladder and anomalous pancreaticobiliary junction. Report of three cases and review of the literature. Hepatogastroenterology 2005;52:1034-8.

10. Frederick LG, David LP, Irvin DF, et al. AJCC Cancer Staging Manual, 6th edn. Philadelphia: Lippincott-Raven, 2002.

11. Mori K, Nagakawa T, Ohta T, et al. Association between gallbladder cancer and anomalous union of the pancreatico-biliary ductal system. Hepatogastroenterology 1993;40:56-60.

12. Hu B, Gong B, Zhou DY. Association of anomalous pancreaticobiliary ductal junction with gallbladder carcinoma in Chinese patients: An ERCP study. Gastrointest Endosc 2003;57:541-5. 
13. Chang LY, Wang HP, Wu MS, et al. Anomalous pancreaticobiliary ductal union - an etiologic association of gallbladder cancer and adenomyomatosis. Hepatogastroenterology 1998;45:2016-9.

14. Lee JH, Chung JB, Lee SJ, et al. Analysis of 45 cases of anomalous pancreaticobiliary ductal union. Kor J Gastroenterol 1998;31:814-21.

15. Sandoh N, Shirai Y, Hatakeyama K. Incidence of anomalous union of the pancreaticobiliary ductal system in biliary cancer. Hepatogastroenterology 1997;44:1580-3.

16. Yamauchi S, Koga A, Matsumoto S, Tanaka M, Nakayama F. Anomalous junction of pancreaticobiliary duct without congenital choledochal cyst: A possible risk factor for gallbladder cancer. Am J Gastroenterol 1987:82;20-4.

17. Lipsett PA, Pitt HA. Surgical treatment of choledochal cyst. J Hepatobiliary Pancreat Surg 2003;10:352-9.
18. Shimada K, Yanagisawa J, Nakayama F. Increased lysophosphatidylcholine and pancreatic enzyme content in bile of patients with anomalous pancreaticobiliary ductal junction. Hepatology 1991;13:438-44.

19. Tanno S, Obara T, Fujii T, et al. Proliferative potential and K-ras mutation in epithelial hyperplasia of the gallbladder in patients with anomalous pancreaticobiliary duct union. Cancer 1998;83:267-75.

20. Hanada K, Itoh M, Fujii K, Tsuchida A, Ooishi H, Kajiyama G. $\mathrm{K}$-ras and $p 53$ mutations in stage I gallbladder carcinoma with an anomalous junction of the pancreaticobiliary duct. Cancer 1996;77:452-8.

21. Tazuma S, Kajiyama G. Carcinogenesis of malignant lesions of the gall bladder. The impact of chronic inflammation and gallstones. Langenbecks Arch Surg 2001;386:224-9. 


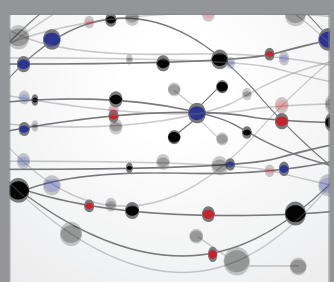

The Scientific World Journal
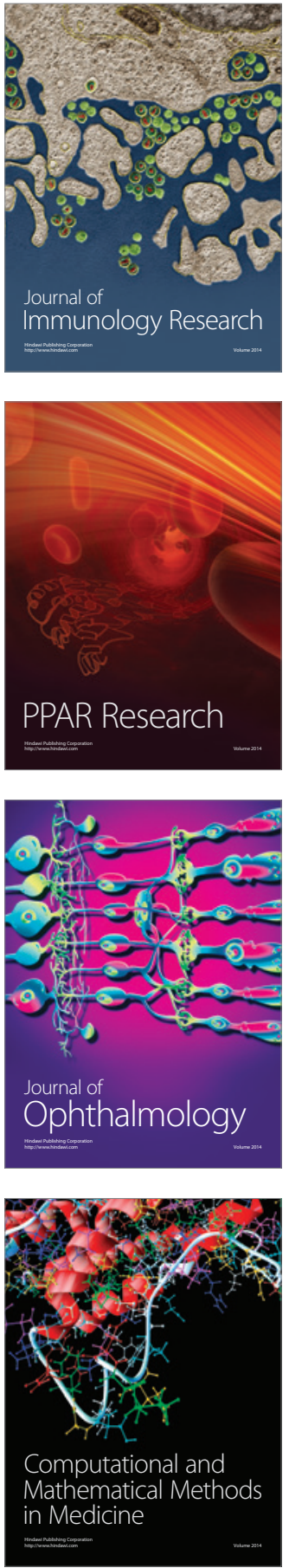

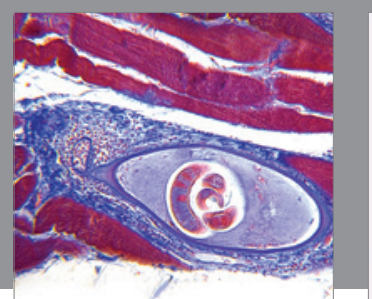

Gastroenterology Research and Practice

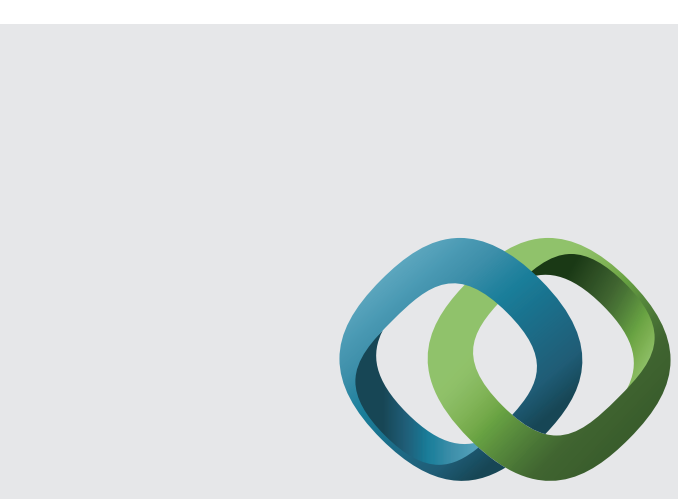

\section{Hindawi}

Submit your manuscripts at

http://www.hindawi.com
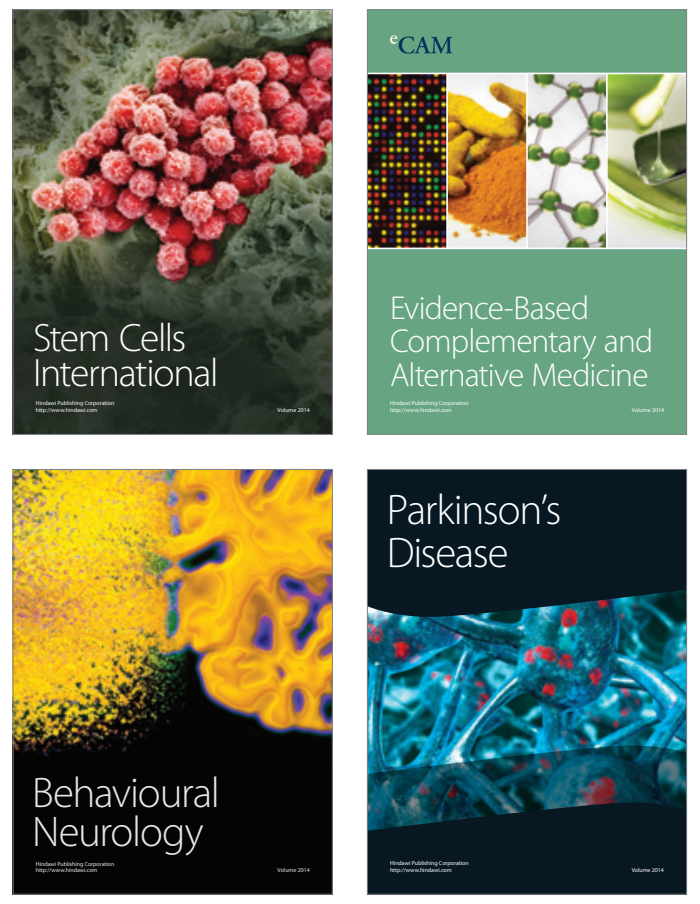
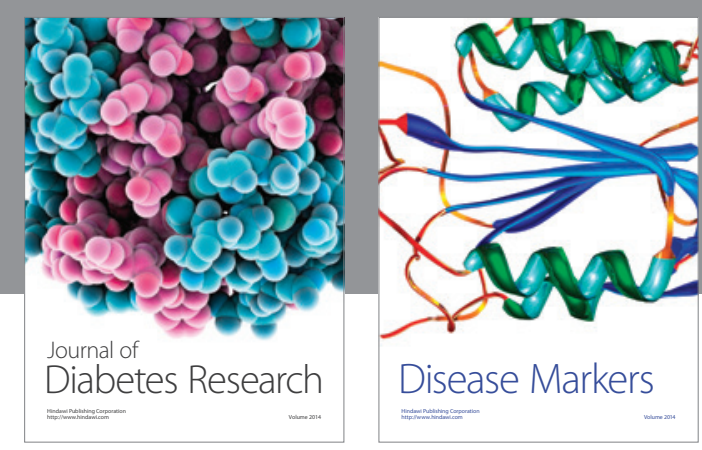

Disease Markers
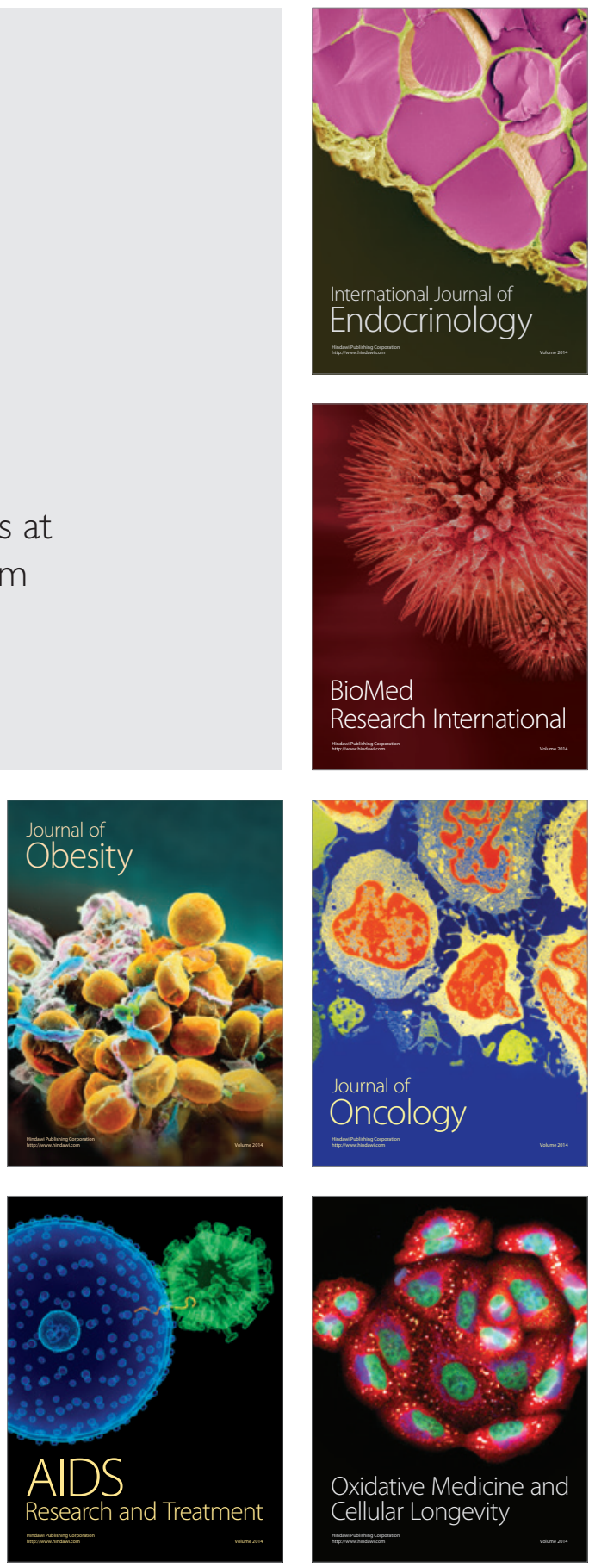